\title{
Tuning Aerosol Particle Size Distribution of Metered Dose Inhalers Using Cosolvents and Surfactants
}

\author{
Imran Y. Saleem ${ }^{1}$ and Hugh D. C. Smyth ${ }^{2}$ \\ ${ }^{1}$ School of Pharmacy \& Biomolecular Sciences, Liverpool John Moores University, Liverpool L3 3AF, UK \\ ${ }^{2}$ Division of Pharmaceutics, College of Pharmacy, University of Texas at Austin, Austin, TX 78712-1113, USA \\ Correspondence should be addressed to Imran Y. Saleem; i.saleem@ljmu.ac.uk
}

Received 26 March 2013; Accepted 2 July 2013

Academic Editor: Christine Dufès

Copyright (c) 2013 I. Y. Saleem and H. D. C. Smyth. This is an open access article distributed under the Creative Commons Attribution License, which permits unrestricted use, distribution, and reproduction in any medium, provided the original work is properly cited.

\begin{abstract}
Objectives. The purpose of these studies was to understand the influence of cosolvent and surfactant contributions to particle size distributions emitted from solution metered dose inhalers (pMDIs) based on the propellant HFA 227. Methods. Two sets of formulations were prepared: (a) pMDIs-HFA 227 containing cosolvent (5-15\% w/w ethanol) with constant surfactant (pluronic) concentration and (b) pMDIs-HFA 227 containing surfactant $(0-5.45 \% \mathrm{w} / \mathrm{w}$ pluronic) with constant cosolvent concentration. Particle size distributions emitted from these pMDIs were analyzed using aerodynamic characterization (inertial impaction) and laser diffraction methods. Results. Both cosolvent and surfactant concentrations were positively correlated with median particle sizes; that is, drug particle size increased with increasing ethanol and pluronic concentrations. However, evaluation of particle size distributions showed that cosolvent caused reduction in the fine particle mode magnitude while the surfactant caused a shift in the mode position. These findings highlight the different mechanisms by which these components influence droplet formation and demonstrate the ability to utilize the different effects in formulations of pMDI-HFA 227 for independently modulating particle sizes in the respirable region. Conclusion. Potentially, the formulation design window generated using these excipients in combination could be used to match the particle size output of reformulated products to preexisting pMDI products.
\end{abstract}

\section{Introduction}

Pressurized metered dose inhalers (pMDIs) have found frequent application in the delivery of therapeutics for treatment of pulmonary diseases, such as asthma and chronic obstructive pulmonary disease [1]. They are compact and have the potential to deliver a wide range of doses and drugs [2]. In general, pMDI formulations comprise a therapeutic material, a propellant, cosolvents, and surfactants toprevent drugaerosol coagulation and lubricate moving parts of the metering valve.

Historically, pMDIs propellants were ozone-depleting chlorofluorocarbons (CFCs) [3]. This prompted the welldocumented search for more environmentally friendly alternatives, such as the biocompatible, nonozone depleting hydrofluoroalkanes (tetrafluoroethane [HFA-134] and heptafluoropropane [HFA 227]) [4, 5]. Many of the presently marketed pMDIs contain HFA-134, as it was the first propellant to have full term toxicity testing [6]. However, despite some similarities in densities and vapor pressures, the physicochemical properties of HFAs and CFCs differ significantly $[7,8]$, leading to incompatibilities with traditional excipients, canister components, and valve elastomers. This has led to difficulties for reformulators trying to match the performance of newer generation formulations to those they are attempting to replace. The particle size distribution of inhalation aerosols is a critical parameter that needs to be carefully controlled since it determines where the aerosol will deposit in the respiratory tract and is closely linked to the efficacy as well as the side effects of the delivered medication as evidenced by the CFC to HFA transition $[9,10]$. Furthermore, the particle size distribution of a pMDI aerosol depends on the physicochemical properties of the formulation [11]. Thus, reformulating pMDIs from CFCs to HFAs has been problematic, 
particularly when attempts have been made to match the performance of these two systems (aerosol output equivalence). This approach of reformulating pMDIs based on bioequivalency to the CFC pMDIs they have replaced was adopted by most companies involved in the transition from CFC to HFAs [8]. To achieve equivalence, there are two general strategies which can be used to modulate aerosol output and lung deposition of pMDIs; the first is altering the formulation parameters such as propellant and excipients which we have previously reviewed $[8,11]$. Secondly, device design can be changed rationally to induce changes in aerosol output as we have previously shown for actuator nozzle dimensions [12, 13].

Part of the issue for matching deposition profiles of different products has been the difficulty in matching aerosol output beyond the mass median aerodynamic diameters and other composite measures such as fine particle fraction or respirable fractions. Indeed, it has been reported that HFA134 solution formulations displayed multimodal particle size distributions. In these studies, varying cosolvent concentrations in HFA-134/ethanol pMDIs influenced particle size distribution but did not cause particle size modes to shift $[5,11]$. This is problematic for formulators wishing to show equivalence with monomodal aerosols since changes in particle size output modulated by use of cosolvents alone will be insufficient to obtain a match of aerosol deposition profiles.

In the current studies, we show that by controlling both cosolvent and surfactant concentrations, the aerosol particle size distributions can be modulated both along the $x$ and $y$ axes; that is, HFA 227 solution formulations can be tuned within a performance space. Specifically, the aim of these studies was to investigate the influence of changing the concentrations of a model surfactant (Pluronic L81) and ethanol on the emitted particle size distribution and in vitro aerosol deposition studies.

\section{Materials and Methods}

2.1. Materials. The propellant 1,1,1,2,3,3,3-heptafluoropropane (HFA 227) was provided as a gift from Solvay Fluorides Inc. (Houston, TX, USA). Fluorescein sodium (fluorescein $\mathrm{Na}$ ) was purchased from Sigma-Aldrich (St. Louis, MO, USA). Ethanol (EtOH) (HPLC grade) and methanol (HPLC grade) were purchased from VWR (West Chester, PA, USA). Aluminium aerosol canisters and metered dose valves $(25 \mu \mathrm{L})$ were provided as a gift from Valois Pharmaceuticals (Marlyle-Roi, France). Pluronic L81 was a gift from BASF Corp (Parsippany, NJ, USA).

2.2. Preparation of Pressurised Metered Dose Inhalers ( $p M D I s$ ). A series of formulations were prepared (Table 1) containing various amounts by weight of Pluronic L81 and HFA 227 propellant with constant ethanol concentration (\% w/w) and fluorescein Na drug mass (\% w/w), as a model drug. Table 2 represents formulations consisting of different ethanol concentrations $(\% \mathrm{w} / \mathrm{w})$ but maintaining constant Pluronic L81 (\% w/w) and fluorescein $\mathrm{Na}(\% \mathrm{w} / \mathrm{w})$ concentrations. Significant preformulation, solubility, and stability studies
TABLE 1: Composition of HFA 227 formulations maintaining constant fluorescein $\mathrm{Na}$ and ethanol concentration $(n=3)$.

\begin{tabular}{lccc}
\hline Formulation & $\begin{array}{c}\text { Pluronic L81 } \\
(\% \mathrm{w} / \mathrm{w})\end{array}$ & $\begin{array}{c}\text { Ethanol } \\
(\% \mathrm{w} / \mathrm{w})\end{array}$ & $\begin{array}{c}\text { Fluorescein Na } \\
(\% \mathrm{w} / \mathrm{w})\end{array}$ \\
\hline $1.22 \%$ w/w Pluronic L81 & 1.22 & 13.3 & 0.04 \\
$5.45 \%$ w/w Pluronic L81 & 5.45 & 13.4 & 0.04 \\
$0 \%$ w/w Pluronic L81 & $0^{*}$ & 13.3 & 0.04 \\
\hline
\end{tabular}

${ }^{*}$ Formulation $0 \% \mathrm{w} / \mathrm{w}$ Pluronic L81 contained $1.22 \% \mathrm{w} / \mathrm{w}$ of deionized water as a replacement for Pluronic L81 to maintain mass balance.

TABLE 2: Composition of HFA 227 formulations maintaining constant Pluronic L81 and fluorescein Na concentrations $(n=3)$.

\begin{tabular}{lccc}
\hline Formulation & $\begin{array}{c}\text { Pluronic L81 } \\
(\% \mathrm{w} / \mathrm{w})\end{array}$ & $\begin{array}{c}\text { Ethanol } \\
(\% \mathrm{w} / \mathrm{w})\end{array}$ & $\begin{array}{c}\text { Fluorescein Na } \\
(\% \mathrm{w} / \mathrm{w})\end{array}$ \\
\hline $5 \% \mathrm{w} / \mathrm{w} \mathrm{EtOH}$ & 5 & 5 & 0.04 \\
$10 \% \mathrm{w} / \mathrm{w} \mathrm{EtOH}$ & 5 & 10 & 0.04 \\
$13 \% \mathrm{w} / \mathrm{w} \mathrm{EtOH}$ & 5 & 13 & 0.04 \\
$15 \% \mathrm{w} / \mathrm{w} \mathrm{EtOH}$ & 5 & 15 & 0.04 \\
\hline
\end{tabular}

were performed to ensure compatibility of the model drug, excipients, and propellants (data not shown).

Aliquots of Pluronic L81, ethanol, and fluorescein $\mathrm{Na}$, as represented in Tables 1 and 2, were added by weight to aluminium aerosol canisters. Metered dose valves were then crimped onto the canisters using a manual canister crimper (Aero-Tech Laboratory Equipment Company, Worcester, NY) and filled with the desired weight of HFA 227 propellant using a pressure burette (Aero-Tech Laboratory Equipment Company, Worcester, NY, USA). All canisters were equipped with a $0.33 \mu \mathrm{m}$ actuator (Valois Pharmaceuticals, Marly-leRoi, France) and prepared on the same day as testing.

\subsection{Particle Size Analysis of Drug (Fluorescein Na) Using Laser} Diffraction. Particle size characteristics of each of the formulations were determined using a Sympatec Helos laser diffraction instrument (Sympatec GmbH, Germany). The pMDI was positioned at a set distance from the laser beam and at a fixed height ensuring that the aerosol plume was projected across the laser. This was achieved by placing the aerosol device such that the actuator orifice was within the lens cutoff distance and was aligned with the height of the laser path. Particle size distribution was measured using four actuations shaking the canister between actuations five times and expressed as the volume median diameter (VMD) $(n=4)$.

\subsection{Aerodynamic Particle Size Distributions of Drug (Flu-} orescein $\mathrm{Na}$ ) Using the Next Generation Impactor (NGI). Aerodynamic particle size distributions were determined from cascade impaction studies using a Next Generation Impactor (NGI) (MSP Corp, MN, USA) containing a United States Pharmacopeia induction port and operated at a flow rate of $30 \mathrm{~L} / \mathrm{min}$, precalibrated using a Gilmont Flowmeter Base Model F-4001 (Barnant Company, Barrington, IL, USA). The metering valves were primed by discharging three shots to waste. The pump was switched on 5 seconds prior to 
TABLE 3: Comparison of formulations with different concentrations of Pluronic L81 (data represent mean $\pm \mathrm{SD}, n=3$ ).

\begin{tabular}{lccc}
\hline & \multicolumn{3}{c}{ Pluronic L81 Concentration $(\% \mathrm{w} / \mathrm{w})$} \\
& 0 & 1.22 & 5.45 \\
\hline ED $(\mu \mathrm{g})$ & $170.69 \pm 21.85^{* *}$ & $211.14 \pm 9.63$ & $215.14 \pm 11.55$ \\
FPF $(\%)$ & $49.63 \pm 2.00$ & $50.72 \pm 0.69$ & $33.20 \pm 3.37^{*}$ \\
FPD $(\mu \mathrm{g})$ & $84.61 \pm 10.19$ & $107.05 \pm 3.53$ & $71.17 \pm 3.79^{\#}$ \\
MMAD $(\mu \mathrm{m})$ & $1.56 \pm 0.05^{\$}$ & $3.70 \pm 0.08^{\$}$ & $5.93 \pm 0.49^{\$}$ \\
GSD & $3.22 \pm 0.31$ & $2.00 \pm 0.05$ & $1.78 \pm 0.07$ \\
VMD $(\mu \mathrm{m})$ & $7.07 \pm 0.14$ & $8.39 \pm 0.11$ & $11.04 \pm 0.46^{*}$ \\
\hline
\end{tabular}

ED: emitted dose, MMAD: mass median aerodynamic diameter, FPF: fine particle fraction, FPD: fine particle dose, and GSD: geometric standard deviation. ${ }^{* *} P<0.05$ (ANOVA/Tukey's) $0 \% \mathrm{w} / \mathrm{w}$ Pluronic L81 versus 1.22 and $5.45 \% \mathrm{w} / \mathrm{w}$ Pluronic L81, ${ }^{*} P<0.05$ (ANOVA/Tukey's) $5.45 \%$ $\mathrm{w} / \mathrm{w}$ Pluronic L81 versus 0 and $1.22 \% \mathrm{w} / \mathrm{w}$ Pluronic L81, ${ }^{*} P<0.05$ (ANOVA/Tukey's) $5.45 \% \mathrm{w} / \mathrm{w}$ Pluronic L81 versus $1.22 \% \mathrm{w} / \mathrm{w}$ Pluronic L81, and ${ }^{\$} P<0.05$ comparing all formulations.

pMDI discharge, and pMDI was actuated ten times $(n=3)$. The emitted dose (ED) was expressed as the total mass of drug emitted from the inhaler. The fine particle fraction (\% FPF) (defined as the mass of drug deposited $\left(d_{\mathrm{ae}} \leq 4.6 \mu \mathrm{m}\right)$ was expressed as a percentage of the emitted dose and the fine particle dose (FPD) was expressed as the mass of drug deposited in the NGI $\left(d_{\mathrm{ae}} \leq 4.6 \mu \mathrm{m}\right)$. Furthermore, inertial impaction data was also subjected to log-probability analysis to allow the derivation of mass median aerodynamic diameter (MMAD) and geometric standard deviation (GSD) for each formulation [14].

2.5. Chemical Analysis. Fluorescein Na captured on the actuator, induction port, and stages was extracted with methanol (HPLC grade). The aerodynamic particle size distribution was determined by analyzing each of the collected samples for fluorescein Na content by HPLC using a Hitachi Elite LaChrom (Hitachi, CA, USA) with UV detection at $490 \mathrm{~nm}$ using a Kromasil C8 column $(150 \mathrm{~mm} \times 4.6 \mathrm{~mm}$ i.d., Column Engineering, CA, USA). The mobile phase consisted of methanol: water $(60: 40)$ at a flow rate of $1.0 \mathrm{~mL} / \mathrm{min}$, injection volume $10 \mu \mathrm{L}$, and quantification was by peak area using a standard curve in the range $0-25 \mu \mathrm{g} / \mathrm{mL}$.

2.6. Statistical Analysis. The formulations were compared with each other by means of a one-way ANOVA with Tukey's comparison test. The statistical significance level was set at $P \leq 0.05$.

\section{Results}

3.1. Effect of Surfactant Concentration on Particle Size Distributions Emitted from HFA 227 pMDIs. Investigations looked at the influence of altering surfactant levels in the HFA 227 pMDIs on aerosolization and particle size. Laser diffraction data (Table 3) illustrated a direct correlation between increasing surfactant concentration resulting in larger particle size (VMD).

This was further reflected in the MMAD and emitted dose data from cascade impaction studies. However, a significant

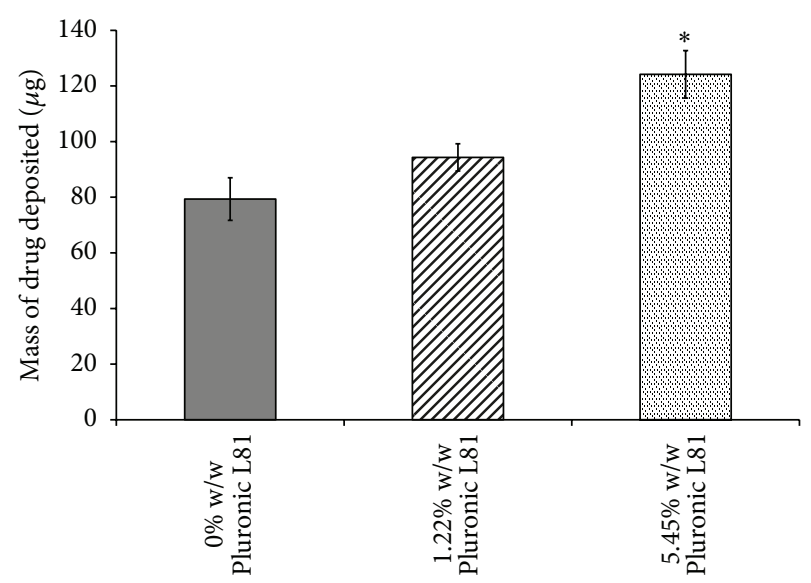

FIGURE 1: Comparison of HFA 227 formulations with varying concentrations of Pluronic L81 in terms of drug deposited in USP throat of NGI maintaining constant concentration of fluorescein $\mathrm{Na}$ and ethanol (data represent mean $\pm \mathrm{SD}, n=3$ ). ${ }^{*} P<0.05$ (ANOVA/Tukey's) 5.45\% w/w Pluronic L81 versus $1.22 \& 0 \% \mathrm{w} / \mathrm{w}$ Pluronic L81.

decrease in FPD and FPF was observed as the surfactant concentration was increased from $1.22 \% \mathrm{w} / \mathrm{w}$ to $5.45 \% \mathrm{w} / \mathrm{w}$ $(P<0.05$, ANOVA/Tukey's). Similarly, USP induction port deposition was positively correlated with surfactant concentrations, with $5.45 \% \mathrm{w} / \mathrm{w}$ Pluronic L81 formulations resulting in significantly greater throat deposition compared to the other formulations $(P<0.05$, ANOVA/Tukey's) (see Figure 1). In addition, increasing the concentration of surfactants caused the fine particle mode (population of particles less than $\sim 10$ microns) to shift along the abscissa. High surfactant concentrations $(5.45 \% \mathrm{w} / \mathrm{w})$ significantly dominated at cutoff diameters $\geq 6.4 \mu \mathrm{m}(P<0.05$, ANOVA/Tukey's), with $1 \%$ w/w Pluronic L81 dominating between $3.99-1.36 \mu \mathrm{m}(P<$ 0.05 , ANOVA/Tukey's) (see Figure 2).

\subsection{Effect of Ethanol Concentration on Particle Size Distri-} butions Emitted from HFA 227 pMDIs. A summary of the studies for fluorescein Na labelled pMDI formulations with varying levels of cosolvent is presented in Table 4 . There was a direct correlation between increasing ethanol concentration resulting in enhanced particle size (VMD) and MMAD, with significant differences noted between formulations containing $15 \% \mathrm{w} / \mathrm{w}$ versus 10 or $5 \% \mathrm{w} / \mathrm{w}$ ethanol $(P<0.05$, ANOVA/ Tukey's).

Although a decrease was noted in MMAD between formulations containing 5 and $10 \% \mathrm{w} / \mathrm{w} \mathrm{EtOH}$, this was not significant $(P>0.05$, ANOVA/Tukey's). Furthermore, as MMAD values increased, this corresponds to a significantly decreased FPD between all formulations from $105.07 \pm 2.31 \mu \mathrm{g}$ to $61.28 \pm 1.79 \mu \mathrm{g}$ (Table 4$)(P<0.05$, ANOVA/Tukey's). In addition, a decrease in FPF was also noted with significant difference comparing formulations with 15 and $13 \% \mathrm{w} / \mathrm{w}$ versus 10 and $5 \% \mathrm{w} / \mathrm{w}$ EtOH $(P<$ 0.05, ANOVA/Tukey's). However, there was no significant difference in emitted doses between the formulations $(P>$ 0.05 , ANOVA/Tukey's). These observations are not surprising 
TABLE 4: Comparison of HFA 227 formulations with different concentrations of ethanol (data represent mean $\pm \mathrm{SD}, n=3$ ).

\begin{tabular}{lccrc}
\hline & & Ethanol concentration $(\% \mathrm{w} / \mathrm{w}) /($ vapor pressure, psi) & \\
& $5(59.8 \mathrm{psi})$ & $10(54.6 \mathrm{psi})$ & $13(52.8 \mathrm{psi})$ & $15(50.2 \mathrm{psi})$ \\
\hline ED $(\mu \mathrm{g})$ & $195.08 \pm 23.25$ & $194.26 \pm 14.19$ & $193.31 \pm 12.44$ & $209.52 \pm 11.02$ \\
FPF $(\%)$ & $54.31 \pm 5.65$ & $45.39 \pm 2.90$ & $35.02 \pm 2.26^{* *}$ & $29.27 \pm 0.77^{*}$ \\
FPD $(\mu \mathrm{g})$ & $105.07 \pm 2.31^{ \pm}$ & $87.91 \pm 1.73^{ \pm}$ & $67.52 \pm 0.38^{ \pm}$ & $61.28 \pm 1.79^{ \pm}$ \\
$\operatorname{MMAD}(\mu \mathrm{m})$ & $5.13 \pm 0.23$ & $5.05 \pm 0.15$ & $5.55 \pm 0.18$ & $5.79 \pm 0.05^{*}$ \\
$\operatorname{GSD}$ & $1.74 \pm 0.12$ & $2.07 \pm 0.01$ & $1.73 \pm 0.03$ & $1.78 \pm 0.01$ \\
$\operatorname{VMD}(\mu \mathrm{m})$ & $5.32 \pm 0.54$ & $8.03 \pm 0.36$ & $9.72 \pm 0.56$ & $12.0 \pm 0.44^{*}$ \\
\hline
\end{tabular}

ED: emitted dose, MMAD: mass median aerodynamic diameter, FPF: fine particle fraction, FPD: fine particle dose, and GSD: geometric standard deviation. ${ }^{*} P<0.05$ (ANOVA/Tukey's) $15 \% \mathrm{w} / \mathrm{w}$ EtOH versus 10 and $5 \% \mathrm{w} / \mathrm{w} \mathrm{EtOH},{ }^{* *} \mathrm{P}<0.05$ (ANOVA/Tukey's) $13 \% \mathrm{w} / \mathrm{w}$ EtOH versus 10 and $5 \% \mathrm{w} / \mathrm{w}$ EtOH, and ${ }^{ \pm} P<0.05$ comparing all formulations (ANOVA/Tukey's).

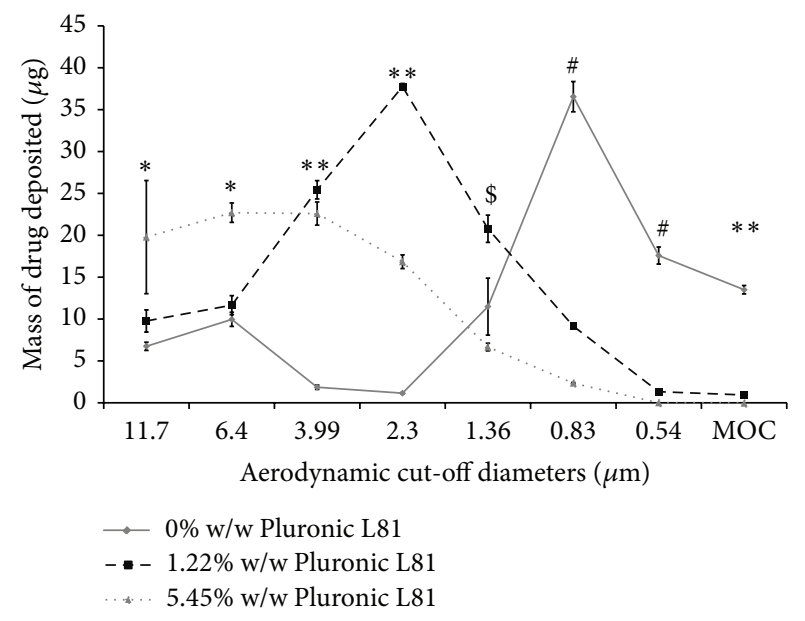

FIGURE 2: Comparison of HFA227 formulations in terms of drug deposited on each stage of Next Generation Impactor, maintaining constant concentration of ethanol (data represent mean $\pm \mathrm{SD}, n=$ 3). MOC: microorifice collector. ${ }^{*} P<0.05$ (ANOVA/Tukey's) $5.45 \% \mathrm{w} / \mathrm{w}$ Pluronic L81 versus 0 and $1.22 \% \mathrm{w} / \mathrm{w}$ Pluronic L81, ${ }^{* *} P<0.05$ (ANOVA/Tukey's) comparing all formulations, ${ }^{\$} P<$ 0.05 (ANOVA/Tukey's) $1 \% \mathrm{w} / \mathrm{w}$ Pluronic L81 versus 0 and $5 \% \mathrm{w} / \mathrm{w}$ Pluronic L81, and ${ }^{\#} P<0.05$ (ANOVA/Tukey's) 0\% w/w Pluronic L81 versus 1.22 and $5 \% \mathrm{w} / \mathrm{w}$ Pluronic L81.

and are consistent with our previous studies conducted using HFA 134a propellants [11]. Thus, as expected with increased particle size, the USP induction port (throat) deposition also increased with increasing ethanol concentrations (see Figure 3). Furthermore, increasing ethanol concentrations in the HFA 227 formulations caused similar changes to the particle size distributions (see Figure 4). Generally, the lower ethanol concentrations ( 5 and $10 \% \mathrm{w} / \mathrm{w}$ ), the greater the mass of drug deposited at cut-off-diameters 6.4 to $0.83 \mu \mathrm{m}$ $(P<0.05$, ANOVA/Tukey's). Importantly, the positions of the particle size modes were not changed as ethanol concentrations are changed, rather their magnitudes were altered. These observations are in contrast to those discussed previously when we varied the surfactant concentration while keeping ethanol concentrations constant.

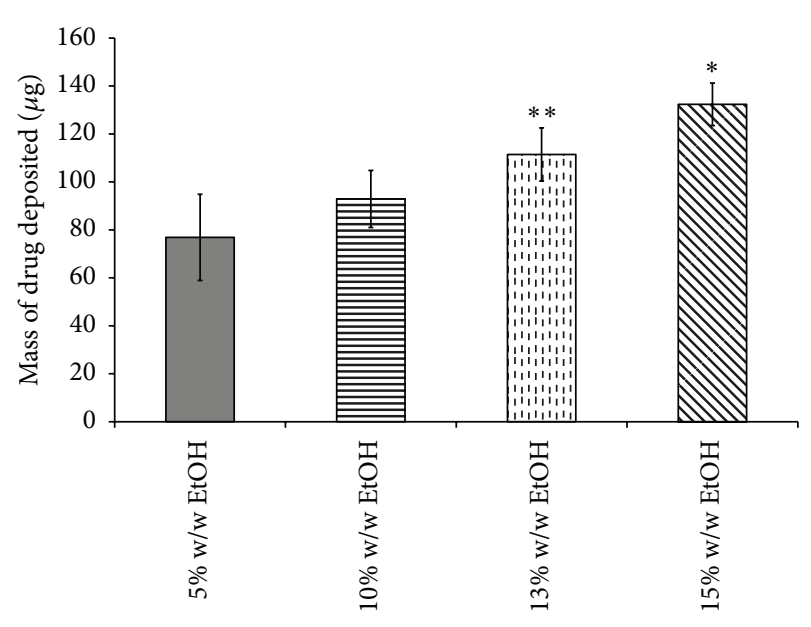

Figure 3: Comparison of HFA 227 formulations in terms of drug deposited in USP throat of NGI maintaining constant concentration of fluorescein $\mathrm{Na}$ and Pluronic L81 (data represent mean $\pm \mathrm{SD}, n=$ 3). ${ }^{*} P<0.05$ (ANOVA/Tukey's) $15 \% \mathrm{w} / \mathrm{w}$ EtOH versus $10 \& 5 \% \mathrm{w} / \mathrm{w}$ EtOH, ${ }^{* *} P<0.05$ (ANOVA/Tukey's) $13 \%$ w/w EtOH versus 5\% w/w $\mathrm{EtOH}$.

\section{Discussion}

This study investigated the effects of ethanol and surfactant (Pluronic L81) concentrations on drug particle size distribution and in vitro drug aerosol deposition using pMDIs containing propellant HFA 227. For solution-based pMDIs, these two excipient classes are common and often necessary for ensuring solubility and performance. Some previous studies have developed predictive models for solution-based formulations [15], but in general, these approaches have been to predict MMAD or fine particle fractions. Due to the dependency of pharmacokinetics and pharmacodynamics of inhaled products on deposition patterns, particularly in the challenging cases of matching performance, it may be more useful to match whole distributions rather than measures of central tendency or respirability.

Although pluronics are not currently used in marketed pMDI products, several recent patents and publications have detailed the use of these surfactants in this manner [16-19]. 


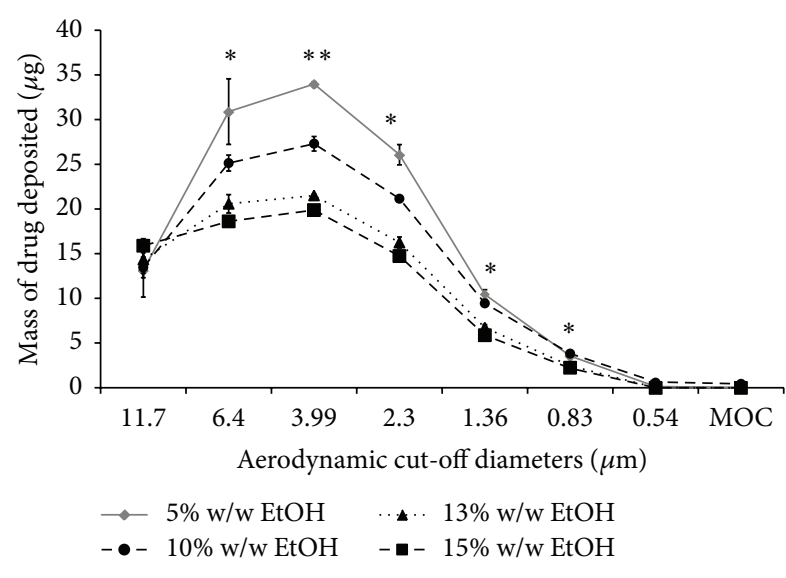

FIGURE 4: The influence of ethanol cosolvent concentrations on the aerodynamic particle size characteristics of HFA 227 formulations as quantified using a Next Generation Impactor. Surfactant concentrations were kept constant (data represent mean $\pm \mathrm{SD}, n=3$ ). MOC: microorifice collector. ${ }^{*} P<0.05$ (ANOVA/Tukey's) $15 \% \mathrm{w} / \mathrm{w}$ EtOH versus 10 and $5 \% \mathrm{w} / \mathrm{w}$ EtOH and ${ }^{* *} \mathrm{P}<0.05$ comparing all formulations.

The main motivation for this work was to determine if the in vitro aerosol performance of these model systems could be adequately modulated using the two components mentioned previously. Several literature reports confirm that increasing either cosolvent or surfactant concentrations resulted in increased emitted particle sizes. We observed that ethanol and the Pluronic L81 surfactant caused very different effects on the emitted particle size distributions when their concentrations were altered. This was significant for several reasons. Firstly, it appears that the mechanisms by which droplet sizes were influenced by cosolvent versus surfactants were very different. Differing mechanisms would indicate that particle size could be manipulated independently using these two approaches. Furthermore, modulating drug particle size is important for either optimizing the performance of these products or matching the performance of products to those already approved by regulatory agencies across the world. Secondly, the pathway to regulatory approval of products (generic or otherwise) appears to focus on stage-by-stage deposition rather than mean or median values that are less sensitive markers of deposition. Therefore, the focus of many studies and literature reports has been MMAD and FPD and the ability to manipulate particle size distribution for lung targeting. This is considered an important aspect of formulation as the Food and Drug Administration (FDA) and other regulatory agencies are interested in cascade impactor stage-by-stage in vitro correlation. In this study, consistent with several previous investigations, we showed that varying concentrations of cosolvent (ethanol) and surfactant (Pluronic L81) caused differences in aerosol particle sizes.

Perhaps the most challenging aspect in reformulating pMDIs, with surfactants traditionally employed in CFCbased pMDIs and found in FDA-approved products, is the limited solubility in the more polar HFAs [7, 20]. Surfactants are generally required in solution and dispersion formulations as solubilising/dispersing agents and as valve lubricants [5]. Cosolvents are generally required in HFAbased formulations to aid in the solubilisation of surfactants [5] which could affect the vapor pressure of pMDI mixtures and thus the aerosol respirable fraction. The development of novel surfactants for HFA-based pMDIs has been limited but several groups focusing on this task using suspension based pMDIs [21], and recently pluronic copolymers have been investigated as potential surfactants in solution based pMDI formulations by Ridder et al. [22] who used Pluronic L81 surfactant and found good solubility in HFA 227.

As Pluronic L81 concentrations were increased, a population modal shift to higher particle sizes was observed. The elevated MMAD and VMD values associated with higher concentrations of Pluronic L81 may be attributed to strong hydrogen bonding between Pluronic L81 and HFA 227 and the surface active nature of Pluronic L81 resulting in decreased evaporation rates from droplet surfaces [8, 23]. Similar to cosolvent effects, another explanation is the decreased propellant fraction leading to reduced vapor pressures and reduction of atomization energy at the nozzle [8]. Consequently, the increase in MMAD and VMD with increasing Pluronic L81 concentration from 1.22 to $5.45 \% \mathrm{w} / \mathrm{w}$ resulted in a greater deposition of drug in the throat, reduced the fraction of emitted dose with $d_{\mathrm{ae}} \leq 4.6 \mu \mathrm{m}$, and hence reduced FPF and FPD. However, there appear to be important differences in the mechanism of particle size modulation between ethanol and Pluronic L81 (see Figures 2 and 4). It can be seen that the effects of increasing surfactant concentration are somewhat different from those patterns observed with cosolvents which had the effect of moving the particle size distributions along the ordinate axis and not the abscissa.

Considerable work on solution formulations has been reported by several groups including Stein et al. from $3 \mathrm{M}$ [24-28]. The correlation of increasing cosolvent concentrations resulting in enhanced particle sizes has been attributed to the reduced energy available for atomization due to the decreased vapor pressures [11] and increased droplet sizes owing to either slow or incomplete evaporation [29] at these time scales. These studies show that ethanol caused a decrease in the relative proportion of fine particles due to the decrease in vapor pressure of the solution as we add ethanol. The amount of fine particles in the aerosol cloud is directly proportional to the square root of the pressureas ethanol concentration increases, the vapor pressure of the solution decreases; hence, the number of fine particles also decreases. This was supported by the observation of greater drug deposition in the USP induction port for formulations of higher ethanol content in our investigations. Moreover, the laser diffraction data (obtained before significant evaporation could occur) appears to support this theory, showing much higher particle sizes than those obtained from cascade impaction studies $[26,30,31]$.

With these differences in mind, we hypothesize that the particle size "fingerprint" for HFA solution formulations may be unique to the excipient selection and relative concentrations. If the mechanisms by which particle size distributions are modulated by cosolvents and surfactants are independent of each other, a design space may be generated for each 


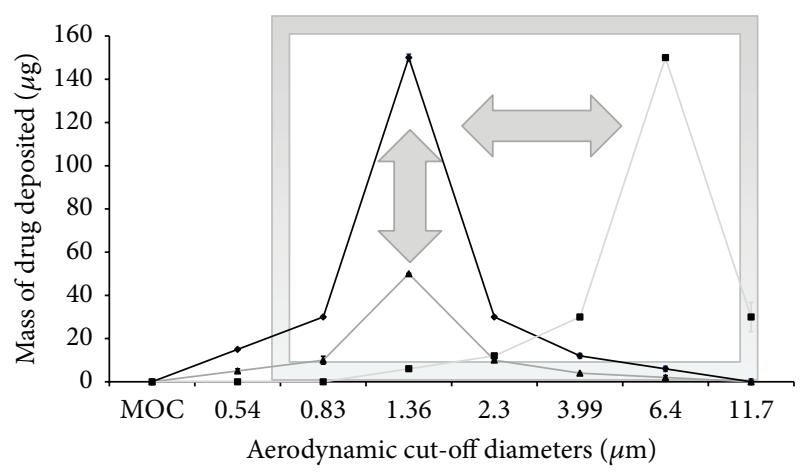

FIGURE 5: Concept of the design window illustrated for solutionbased HFAs containing cosolvent (changing amplitude of the particle size mode, vertical tuning) and surfactants (changing location of the mode, horizontal tuning) in which particle size modulation may be achieved by manipulation of these two components that act through independent mechanisms to effect particle size change.

system (see Figure 5). In terms of reformulation efforts and development of equivalent generic pMDIs, this type of approach could be used to match the stage-by-stage analysis or particle size fingerprint more rapidly. Studies in our labs are currently underway to thoroughly test these hypotheses using surface response analysis.

\section{Conclusion}

The purpose of these studies was to understand cosolvent and surfactant contributions to particle size distributions emitted from solution metered dose inhalers based on the propellant HFA 227. These studies build on several previous published investigations using the propellant HFA 134a. Here, for the first time, we describe how particle size distributions can be modulated differently using two different formulation excipients by shifting size distribution modes to different locations and by modifying the amplitude of the modes. The practical implications of using these excipients to independently modulate particle size distributions are that a formulation window can be generated from which reformulation or bioequivalence research and development can be facilitated.

\section{Acknowledgments}

The authors would like to acknowledge that a portion of this work was performed by them when working at the College of Pharmacy, University of New Mexico, USA. This research received no specific grant from any funding agency in the public, commercial, or not-for-profit sectors.

\section{References}

[1] H. M. Courrier, N. Butz, and T. F. Vandamme, "Pulmonary drug delivery systems: recent developments and prospects," Critical Reviews in Therapeutic Drug Carrier Systems, vol. 19, no. 4-5, pp. 425-498, 2002.
[2] C. A. Dunbar, "Atomization mechanisms of the pressurized metered dose inhaler," Particulate Science and Technology, vol. 15, no. 3-4, pp. 253-271, 1997.

[3] K. J. McDonald and G. P. Martin, "Transition to CFC-free metered dose inhalers-into the new millennium," International Journal of Pharmaceutics, vol. 201, no. 1, pp. 89-107, 2000.

[4] T. J. Noakes, "CFC's their replacement and the ozone layer," Journal of Aerosol Medicine, vol. 8, supplement 1, pp. S3-S7, 1995.

[5] C. Vervaet and P. R. Byron, "Drug-surfactant-propellant interactions in HFA-formulations," International Journal of Pharmaceutics, vol. 186, no. 1, pp. 13-30, 1999.

[6] D. J. Alexander, "Safety of propellants," Journal of Aerosol Medicine, vol. 8, no. 1, pp. S29-S34, 1995.

[7] F. E. Blondino and P. R. Byron, "Surfactant dissolution and water solubilization in chlorine-free liquified gas propellants," Drug Development and Industrial Pharmacy, vol. 24, no. 10, pp. 935945, 1998.

[8] H. D. C. Smyth, "The influence of formulation variables on the performance of alternative propellant-driven metered dose inhalers," Advanced Drug Delivery Reviews, vol. 55, no. 7, pp. 807-828, 2003.

[9] C. L. Leach, P. J. Davidson, and R. J. Boudreau, "Improved airway targeting with the CFC-free HFA-beclomethasone metered- dose inhaler compared with CFC-beclomethasone," European Respiratory Journal, vol. 12, no. 6, pp. 1346-1353, 1998.

[10] J. N. Pritchard, "The influence of lung deposition on clinical response," Journal of Aerosol Medicine, vol. 14, no. 1, pp. S19-S26, 2001.

[11] H. D. C. Smyth and A. J. Hickey, "Multimodal particle size distributions emitted from HFA-134a solution pressurized metered-dose inhalers," AAPS PharmSciTech, vol. 4, no. 3, p. E38, 2003.

[12] H. Smyth, G. Brace, T. Barbour, J. Gallion, J. Grove, and A. J. Hickey, "Spray pattern analysis for metered dose inhalers: effect of actuator design," Pharmaceutical Research, vol. 23, no. 7, pp. 1591-1596, 2006

[13] H. Smyth, A. J. Hickey, G. Brace, T. Barbour, J. Gallion, and J. Grove, "Spray pattern analysis for metered dose inhalers I: orifice size, particle size, and droplet motion correlations," Drug Development and Industrial Pharmacy, vol. 32, no. 9, pp. 10331041, 2006.

[14] M. R. Feddah, K. F. Brown, E. M. Gipps, and N. M. Davies, "In-vitro characterisation of metered dose inhaler versus dry powder inhaler glucocorticoid products: influence of inspiratory flow rates," Journal of Pharmacy \& Pharmaceutical Sciences, vol. 3, no. 3, pp. 318-324, 2000.

[15] D. A. Lewis, D. Ganderton, B. J. Meakin, and G. Brambilla, "Theory and practice with soultion systems," Respiratory Drug Delivery IX, vol. 1, pp. 109-116, 2004.

[16] Y. Gao, L. B. Li, and G. Zhai, "Preparation and characterization of Pluronic/TPGS mixed micelles for solubilization of camptothecin," Colloids and Surfaces B, vol. 64, no. 2, pp. 194-199, 2008.

[17] L. Bromberg, "Polymeric micelles in oral chemotherapy," Journal of Controlled Release, vol. 128, no. 2, pp. 99-112, 2008.

[18] A. V. Kabanov, E. V. Batrakova, and V. Y. Alakhov, "Pluronic block copolymers as novel polymer therapeutics for drug and gene delivery," Journal of Controlled Release, vol. 82, no. 2-3, pp. 189-212, 2002.

[19] U. Chokshi, P. Selvam, L. Porcar, and S. R. P. da Rocha, "Reverse aqueous emulsions and microemulsions in HFA227 propellant 
stabilized by non-ionic ethoxylated amphiphiles," International Journal of Pharmaceutics, vol. 369, no. 1-2, pp. 176-184, 2009.

[20] P. A. Dickinson, P. C. Seville, H. McHale, N. C. Perkins, and G. Taylor, "An investigation of the solubility of various compounds in the hydrofluoroalkane propellants and possible model liquid propellants," Journal of Aerosol Medicine, vol. 13, no. 3, pp. 179$186,2000$.

[21] D. Traini, P. M. Young, P. Rogueda, and R. Price, "Investigation into the influence of polymeric stabilizing excipients on interparticulate forces in pressurised metered dose inhalers," International Journal of Pharmaceutics, vol. 320, no. 1-2, pp. 58-63, 2006.

[22] K. B. Ridder, C. J. Davies-Cutting, and I. W. Kellaway, "Surfactant solubility and aggregate orientation in hydrofluoroalkanes," International Journal of Pharmaceutics, vol. 295, no. 1-2, pp. 5765, 2005.

[23] R. N. Dalby and P. R. Byron, "Comparison of output particle size distributions from pressurized aerosols formulated as solutions or suspensions," Pharmaceutical Research, vol. 5, no. 1, pp. 3639, 1988.

[24] S. W. Stein, "Estimating the number of droplets and drug particles emitted from MDIs," AAPS PharmSciTech, vol. 9, no. 1, pp. 112-115, 2008.

[25] S. W. Stein, "Aiming for a moving target: challenges with impactor measurements of MDI aerosols," International Journal of Pharmaceutics, vol. 355, no. 1-2, pp. 53-61, 2008.

[26] S. W. Stein and P. B. Myrdal, "A theoretical and experimental analysis of formulation and device parameters affecting solution MDI size distributions," Journal of Pharmaceutical Sciences, vol. 93, no. 8, pp. 2158-2175, 2004.

[27] W. S. Stephen, "Size distribution measurements of metered dose inhalers using Andersen Mark II cascade impactors," International Journal of Pharmaceutics, vol. 186, no. 1, pp. 43-52, 1999.

[28] B. J. Gabrio, S. W. Stein, and D. J. Velasquez, "A new method to evaluate plume characteristics of hydrofluoroalkane and chlorofluorocarbon metered dose inhalers," International Journal of Pharmaceutics, vol. 186, no. 1, pp. 3-12, 1999.

[29] S. W. Stein and P. B. Myrdal, "The relative influence of atomization and evaporation on metered dose inhaler drug delivery efficiency," Aerosol Science and Technology, vol. 40, no. 5, pp. 335-347, 2006.

[30] A. H. de Boer, D. Gjaltema, P. Hagedoorn, and H. W. Frijlink, "Characterization of inhalation aerosols: a critical evaluation of cascade impactor analysis and laser diffraction technique," International Journal of Pharmaceutics, vol. 249, no. 1-2, pp. 219231, 2002.

[31] V. Naini, S. Chaudhry, J. Berry, S. Sharpe, J. Hart, and J. Sequeira, "Entry port selection for detecting particle size differences in metered dose inhaler formulations using cascade impaction," Drug Development and Industrial Pharmacy, vol. 30, no. 1, pp. 75-82, 2004. 

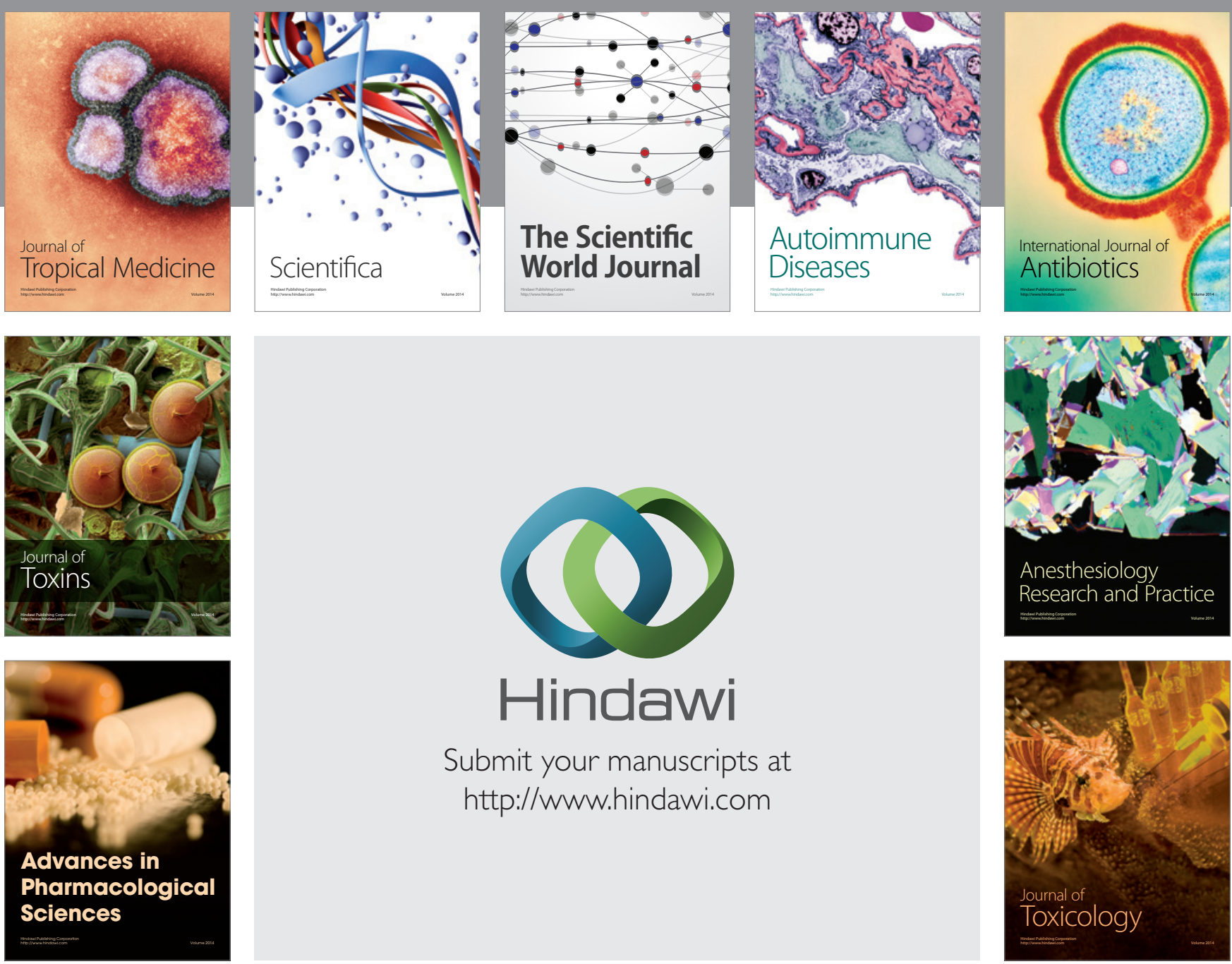

\section{Hindawi}

Submit your manuscripts at

http://www.hindawi.com
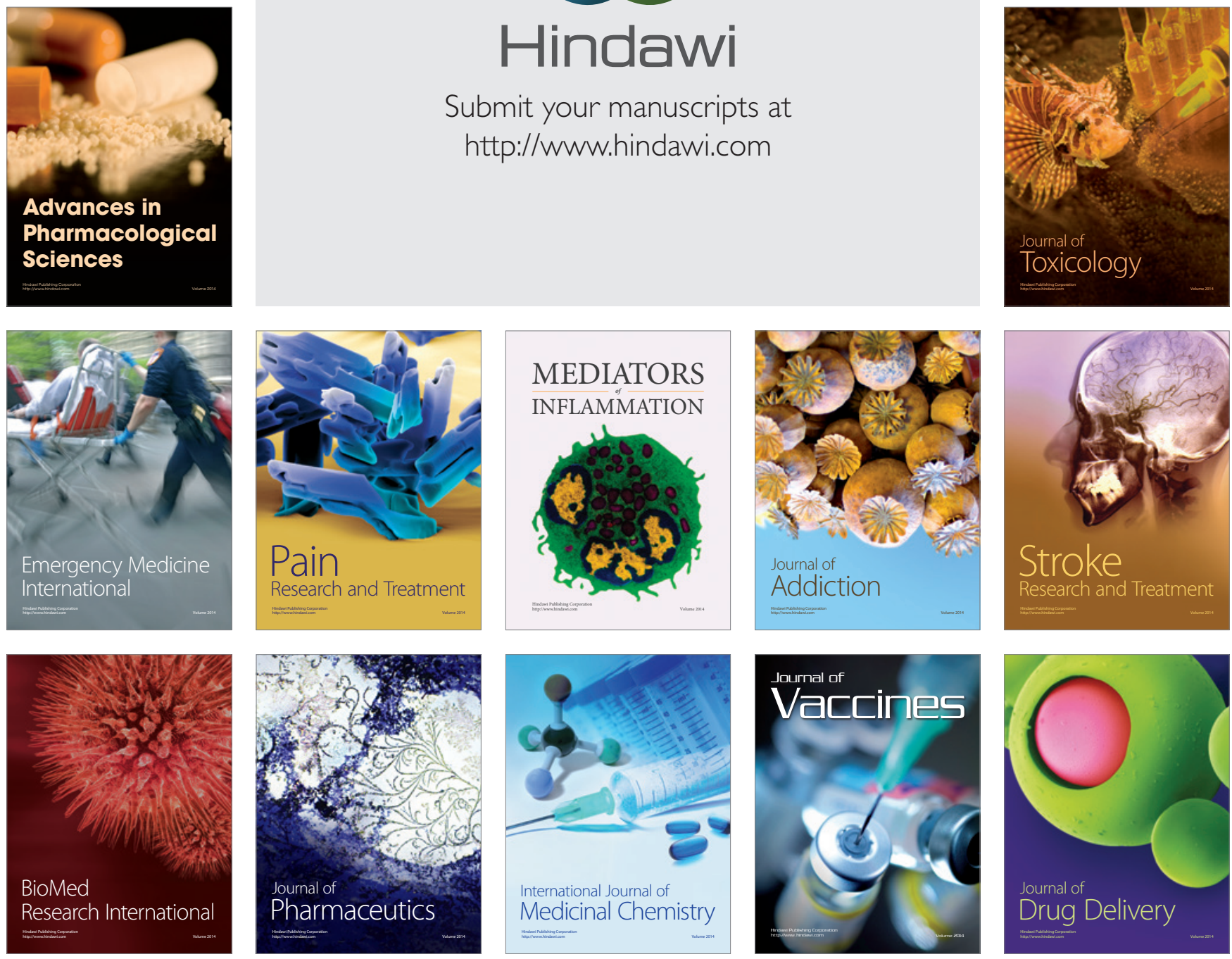